\title{
Excedente hídrico em diferentes solos e épocas de semeadura do girassol no Rio Grande do Sul
}

\author{
Dionéia Daiane Pitol Lucas(1), Arno Bernardo Heldwein ${ }^{(2)}$, Ivan Carlos Maldaner ${ }^{(3)}$, \\ Roberto Trentin ${ }^{(4)}$, Fernando Dill Hinnah ${ }^{(5)}$ e Jocélia Rosa da Silva ${ }^{(2)}$
}

\begin{abstract}
(1)Secretaria da Agricultura e Pecuária do Estado do Rio Grande do Sul, Rua Benjamin Constant, no 476, CEP 98300-000 Palmeira das Missões, RS, Brasil. E-mail: dio.pitol@gmail.com (2)Universidade Federal de Santa Maria, Centro de Ciências Rurais, Departamento de Fitotecnia, Avenida Roraima, o⒈000, CEP 97105-900 Santa Maria, RS, Brasil. E-mail: heldweinab@smail.ufsm.br, joceliarosa.s@gmail.com (3)Instituto Federal de Educação, Ciência e Tecnologia Farroupilha, Campus São Vicente do Sul, Rua 20 de Setembro, s/no, CEP 97420-000 São Vicente do Sul, RS, Brasil. E-mail: ivan.maldaner@svs.iffarroupilha.edu.br (4)Universidade Federal de Pelotas, Faculdade de Agronomia Eliseu Maciel, Campus Universitário, s/no, CEP 96160-000 Capão do Leão, RS, Brasil. E-mail: roberto.trentin@ufpel.edu.br (5)Universidade de São Paulo, Escola Superior de Agricultura Luiz de Queiroz, Avenida Pádua Dias, no 11, CEP 13418-900 Piracicaba, SP, Brasil. E-mail: fhinnah@bol.com.br
\end{abstract}

Resumo - O objetivo deste trabalho foi identificar datas de semeadura com menor ocorrência média de dias com excedente hídrico para a cultura do girassol, e determinar a persistência de dias consecutivos com excedente hídrico ao se considerar a capacidade de armazenamento de água disponível de diferentes solos da região central do Rio Grande do Sul. O desenvolvimento da cultura e o aprofundamento do sistema radicular foram simulados de acordo com a soma térmica para 14 datas de semeadura, de agosto até meados de fevereiro, com dados de 1968 até 2011. A partir da capacidade de armazenamento de água disponível para as diferentes classes de solos da região, calculou-se o balanço hídrico sequencial diário para determinar os dias com excesso hídrico. Avaliou-se a ocorrência de dias com excesso hídrico em diferentes subperíodos de desenvolvimento da cultura, e procedeu-se à análise exploratória com gráficos box-plot para determinação da persistência de dias consecutivos com excesso hídrico durante todo o ciclo da cultura. O excedente hídrico limita o cultivo de girassol em determinadas áreas e períodos na região central do Rio Grande do Sul. A persistência de dias consecutivos com excedente hídrico e a duração do ciclo de desenvolvimento da cultura são influenciados pela data de semeadura.

Termos para indexação: Helianthus annuus, balanço hídrico sequencial, capacidade de armazenamento de água, encharcamento do solo, modelos de crescimento, zoneamento de risco climático.

\section{Water excess in different soils and sowing times for sunflower in the state of Rio Grande do Sul, Brazil}

\begin{abstract}
The objective of this work was to identify sowing dates with the lowest average occurrence of days with water excess for sunflower crop, and to determine the persistence of consecutive days with water excess considering the available water storage capacity of different soils of the central region of the state of Rio Grande do Sul, Brazil. Crop development and root system deepening were simulated based on thermal summation for 14 sowing dates, from August until mid-February, with data from 1968 to 2011. From the available water storage capacity of the different soil classes of the region, the sequential daily water balance was calculated to determine the days with water excess. The occurrence of days with water excess was evaluated in different crop development sub-periods, and exploratory analysis with box-plot graphs was performed to determine the persistence of consecutive days with water excess during the crop cycle. Water excess limits sunflower cultivation in some areas and periods in the central region of the state of Rio Grande do Sul. The persistence of consecutive days with water excess and the duration of the crop development cycle are influenced by the sowing date.
\end{abstract}

Index terms: Helianthus annuus, sequential water balance, water storage capacity, soil waterlogging, growth models, climatic risk zoning.

\section{Introdução}

A condição de excedente hídrico no solo constitui uma restrição ambiental economicamente importante para a produção agrícola, além de ser um dos principais determinantes da distribuição das espécies na natureza (Jackson \& Colmer, 2005; Irfan et al., 2010). Dessa forma, o excedente hídrico associado ao excesso de chuva afeta a produtividade das culturas, uma vez que interfere no crescimento e no desenvolvimento 
das plantas, que ficam sujeitas a condições de hipoxia ou anoxia (Wample \& Davis, 1983). Além disso, ele potencializa a ocorrência de doenças, dificulta o controle destas e de plantas daninhas, e aumenta os problemas com lixiviação de nutrientes (Silveira et al., 2014).

Elevado volume de chuvas, manejo deficiente, sistemas de irrigação inadequados, topografia desfavorável e solo com drenagem natural deficiente ou com problemas de compactação são condições favoráveis ao encharcamento. O conhecimento da distribuição espaço-temporal de chuvas, relacionado ao conhecimento da distribuição dos solos, é fundamental para a gestão sustentável dos recursos hídricos, bem como para a mitigação da ocorrência de excedentes hídricos na agricultura (Saue \& Kadaja, 2009).

A ausência de excedente hídrico é um dos fatores determinantes para o sucesso do cultivo do girassol (Helianthus annuus L.). Loose et al. (2010) verificaram que a produção de girassol, em diferentes regiões da Argentina, é fortemente afetada pelo excesso de chuvas e sensível a diferentes fenômenos atmosféricos em macroescala. $\mathrm{O}$ efeito do estresse por saturação hídrica do solo sobre as plantas de girassol é complexo e depende do estádio de desenvolvimento da planta e da duração do estresse (Orchard \& Jessop, 1984; Grassini et al., 2007; Yasumoto et al., 2011). Quando o excedente hídrico ocorre durante o enchimento de grãos, por exemplo, há maior senescência das folhas e redução tanto na taxa fotossintética das remanescentes na planta, quanto na biomassa de raízes e no rendimento de aquênios (Grassini et al., 2007). Portanto, o conhecimento da ocorrência de excedentes hídricos é considerado de grande importância na determinação de datas de semeadura do girassol.

Apesar da sensibilidade da cultura do girassol ao excedente hídrico, sua utilização em rotação com a cultura do arroz irrigado tem aumentado em países tradicionais nesse cultivo (Yasumoto et al., 2011). Ao invés de se buscar alternativas na engenharia, para eliminar o excesso de água no sistema, ou no planejamento, para restringir a produção de culturas não adaptadas em solos sujeitos ao excedente hídrico, estudos probabilísticos permitem determinar épocas, ou tipos de solos, que apresentam menores chances de ocorrência dessas condições. Não foram localizados trabalhos com esse tipo de análise, para o girassol, no Brasil.

O objetivo deste trabalho foi identificar datas de semeadura com menor ocorrência média de dias com excedente hídrico para a cultura do girassol, e determinar a persistência de dias consecutivos com excedente hídrico ao se considerar a capacidade de armazenamento de água disponível de diferentes solos da região central do Rio Grande do Sul.

\section{Material e Métodos}

O estudo foi desenvolvido por meio de análise numérica, tendo-se utilizado modelagem do crescimento e do desenvolvimento do girassol, associada ao cálculo do balanço hídrico sequencial dos solos, em escala diária. A área abrangida pela Estação Climatológica Principal de Santa Maria, RS, foi considerada como referência para o estudo e está compreendida entre as coordenadas $29^{\circ} 23^{\prime} 15^{\prime \prime} \mathrm{S}$ e $30^{\circ} 22^{\prime} 17^{\prime \prime} \mathrm{S}, 54^{\circ} 32^{\prime} 07^{\prime \prime} \mathrm{W}$ e $53^{\circ} 05^{\prime} 20^{\prime \prime} \mathrm{W}$, o que corresponde a uma área de aproximadamente $8.000 \mathrm{~km}^{2}$ (Cardoso, 2005). O clima dessa região é do tipo Cfa, subtropical úmido, sem estação seca definida e com verões quentes, conforme a classificação de Köppen (Heldwein et al., 2009). Os valores médios da temperatura do ar variam de $14,1^{\circ} \mathrm{C}$, em julho, a $24,8^{\circ} \mathrm{C}$, em janeiro, e a precipitação é uniformemente distribuída ao longo do ano, o que caracteriza um regime pluviométrico isoigro, com média anual de precipitação de $1.712 \mathrm{~mm}$ (Buriol et al., 2006).

Diferentes tipos de solo estão presentes na região, em razão das características do material de origem e do relevo. Há, entretanto, predominância de dois tipos de solos: Argissolos, nas unidades de mapeamento Alto das Canas, Júlio de Castilhos, Oásis, São Pedro e Santa Maria; e Planossolos, nas unidades de mapeamento Vacacaí e São Gabriel, com 51 e 34\% da área ocupada, respectivamente. Os demais solos (Neosolo, Chernossolo, Luvissolo e Latossolo) ocupam em torno de $15 \%$ da área estudada (Cardoso, 2005).

Dados diários de evapotranspiração de referência foram utilizados para obtenção do balanço hídrico sequencial, pelo método de Penman-Monteith, e, nos períodos sem dados da velocidade do vento, adotou-se o Penman modificado. Para o cálculo do balanço hídrico, foram incluídos dados de precipitação pluvial diária e da variação na capacidade de armazenamento de água disponível no solo (CAD). Essa variação depende do estádio de desenvolvimento das plantas de girassol e das características físicas do solo. Utilizou-se o valor da precipitação pluvial efetiva para o cálculo, que seguiu metodologia do U.S. Soil Conservation Service (Frizzone \& Andrade Júnior, 2005). 
Como a duração dos subperíodos de desenvolvimento do girassol é altamente dependente da temperatura do ar, a simulação do desenvolvimento foi realizada com uso do método de soma térmica, tendo-se considerado a duração dos subperíodos como função dos valores acumulados desta soma. Para o cálculo da soma térmica diária $\left({ }^{\circ} \mathrm{C}\right.$ por dia), considerou-se um genótipo de ciclo médio, com temperatura base de $3,9^{\circ} \mathrm{C}$ (Maldaner, 2012), temperatura ótima de $27^{\circ} \mathrm{C}$ e temperatura máxima de $34^{\circ} \mathrm{C}$ (Fagundes et al., 2007). Os dados de temperatura média utilizados no modelo foram obtidos a partir da média aritmética entre as temperaturas diárias mínima e máxima do ar. A soma térmica acumulada foi calculada para cada subperíodo de desenvolvimento do girassol, de acordo com Gilmore \& Rogers (1958). A simulação do desenvolvimento das plantas foi realizada para 14 datas de semeadura: primeiro e décimo-sexto dia de cada mês, de 1 de agosto a 16 de fevereiro. A simulação foi feita com os dados de todos os anos considerados no estudo (1968-2011). Os valores obtidos nas simulações foram utilizados para cálculo da variação do coeficiente de cultura e da $\mathrm{CAD}$, tendose considerado o aprofundamento radicular no solo de acordo com a soma térmica (Maldaner, 2012).

Para o cálculo do balanço hídrico, utilizou-se a metodologia de Thornthwaite \& Mather (1955), com roteiro de cálculo similar ao utilizado por Silva et al. (2008). A simulação foi feita para as diferentes datas de semeadura e em função tanto dos dados simulados de crescimento e desenvolvimento das plantas, quanto dos de evapotranspiração da cultura (Tabela 1). Esta foi considerada, nos diferentes estádios, de acordo com o coeficiente de cultura (Maldaner, 2012).

Os valores de CAD inicial e final foram calculados para os diferentes solos das unidades de mapeamento abrangidas no estudo (Tabela 2), tendo-se utilizado os valores de capacidade de campo e de ponto de murcha permanente descritos para os diferentes horizontes e solos, com base nas informações de Cardoso (2005). A CAD inicial foi determinada para a profundidade de $0,10 \mathrm{~m}$, e a CAD final, até a profundidade de $0,60 \mathrm{~m}$ (Maldaner, 2012). Os solos foram agrupados de acordo com seus valores de CAD inicial e final.

A partir dos resultados do balanço hídrico, calculou-se o conteúdo de água presente no solo, para todos os dias do ciclo da cultura, em cada data de semeadura. Determinouse, então, a evapotranspiração real da cultura. Considerouse que houve excesso hídrico quando toda a quantidade de

Tabela 1. Valores de soma térmica acumulada e de coeficientes de cultura para os diferentes subperíodos de desenvolvimento do girassol (Helianthus annuus) em Santa Maria, RS (Maldaner, 2012).

\begin{tabular}{lcc}
\hline Subperíodo & $\begin{array}{c}\text { Soma térmica } \\
\left({ }^{\circ} \mathrm{C} \text { por dia) }\right.\end{array}$ & $\begin{array}{c}\text { Coeficiente } \\
\text { de cultura }\end{array}$ \\
\hline Semeadura até emergência (S-E) & $0-136,8$ & 0,43 \\
Emergência até BFV ${ }^{(1)}$ (E-R1) & $136,9-826,4$ & $0,4316+2,8 \times 10^{-4} \mathrm{ST}$ \\
$\mathrm{BFV}^{(1)}$ ao início da antese (R1-R5.1) & $826,5-1.248,0$ & $-0,2884+1,2 \times 10^{-3} \mathrm{ST}$ \\
Do início ao final da antese (R5.1-R6) & $1.248,1-1.407,8$ & 1,12 \\
Final da antese até $\mathrm{MF}^{(2)}$ (R6-R9) & $1.407,9-1.869,0$ & $2,2547-8,19 \times 10^{-4} \mathrm{ST}$ \\
\hline
\end{tabular}

${ }^{(1)}$ Botão floral visível. ${ }^{(2)}$ Maturação fisiológica.

Tabela 2. Capacidade de armazenamento inicial $\left(\mathrm{CAD}_{\text {in }}\right)$ e final $\left(\mathrm{CAD}_{\mathrm{f}}\right)$ de água disponível no solo, valor da curva número $(\mathrm{CN})$ e classificação dos solos para diferentes unidades de mapeamento na área de abrangência da Estação Climatológica Principal de Santa Maria, RS.

\begin{tabular}{lcccc}
\hline Unidade de mapeamento & CAD $_{\text {in }}(\mathrm{mm})$ & CAD $_{\mathrm{f}}(\mathrm{mm})$ & $\mathrm{CN}^{(1)}$ & Classificação dos solos \\
\hline Charrua & 15 & 45 & 91 & Neossolo Litólico eutrófico típico \\
Ciríaco & 15 & 45 & 91 & Chernossolo Argilúvico férrico típico \\
Guassupi & 15 & 45 & 91 & Neossolo Litólico distro úmbrico fragmentário \\
Júlio de Castilhos & 15 & 45 & 91 & Argissolo Vermelho Amarelo alumínico úmbrico \\
\hline Cerrito & 15 & 60 & 72 & Latossolo Vermelho distrófico típico \\
São Pedro & 15 & 60 & 72 & Argissolo Vermelho distrófico arênico \\
Venda Grande & 15 & 60 & 72 & Chernossolo Argilúvico órtico saprolítico \\
\hline Alto das Canas & 15 & 80 & 91 & Argissolo Vermelho distrófico latossólico \\
Cambaí & 15 & 80 & 91 & Luvissolo Crômico pálico saprolítico \\
\hline Oásis & 22 & 80 & 91 & Argissolo Bruno Acinzentado alumínico típico \\
São Gabriel & 22 & 80 & 91 & Planossolo Háplico eutrófico típico \\
\hline Santa Maria & 22 & 85 & 72 & Argissolo Amarelo alítico típico \\
\hline Vacacaí & 22 & 105 & 72 & Planossolo Háplico eutrófico arênico \\
\hline
\end{tabular}

${ }^{(1)} \mathrm{CN}$ igual a 72 , para solos com teor de areia maior que $50 \%$, e igual a 91 , para solos com teor de areia menor que $50 \%$ (Maldaner, 2012 ). 
água no perfil do solo, não tendo sido evapotranspirada, ficou sujeita à percolação e ao escoamento superficial. Dessa forma, o excesso hídrico ocorreu quando houve quantidade de água no solo superior à $\mathrm{CAD}$, a qual depende do crescimento e do desenvolvimento da cultura. Assim, a ocorrência de excesso hídrico dependeu da precipitação pluvial, das condições atmosféricas e de fatores relacionados às plantas e às características físico-hídricas do solo.

Como os trabalhos com excesso hídrico normalmente avaliam o tempo em que as plantas ficam submetidas ao estresse, o número de dias em que as plantas ficariam sob condição de excedente hídrico foi quantificado, em vez de se considerar os volumes de excesso propriamente. Desse modo, utilizou-se o número de dias com excesso hídrico como indicador de excesso para a cultura, tendose utilizado 2 e 4 dias como referência, seguindo Orchard \& Jessop (1984), Grassini et al. (2007) e Yasumoto et al. (2011). Com os valores diários de excedente hídrico determinados para cada grupo de solos, para as diferentes datas de semeaduras, obtiveram-se os dias com excesso hídrico para os diferentes subperíodos de desenvolvimento da cultura avaliados: semeadura à emergência (S-E); emergência ao botão floral visível (E-R1); botão floral visível ao início da antese (R1-R5.1); início da antese ao final da antese (R5.1-R6); final da antese à maturação fisiológica (R6-R9); e ciclo completo (S-R9).

Os cálculos foram realizados a partir de "scripts" no aplicativo SAS (SAS Institute, 2001). Os dados do número de dias com excesso hídrico foram submetidos à análise de variância, tendo-se considerado os grupos de solos e as datas de semeadura como fatores. As médias foram comparadas pelo teste de Scott \& Knott, o qual permite melhor discriminação entre os tratamentos quando o número destes é elevado. A persistência de dias consecutivos com excedente hídrico também foi quantificada ao longo do ciclo de desenvolvimento do girassol, para todos os grupos de solos, nos anos avaliados. Para essa análise, foram utilizados gráficos "box-plot". Essa metodologia permite uma análise exploratória dos dados, por meio da visualização da dispersão, da assimetria e da discrepância dos dados em torno da média, e também permite a visualização dos agrupamentos de tratamentos avaliados. Foram apresentados os valores de mediana (posição central do gráfico), primeiro e terceiro quartil (assimetria da distribuição) e valor mínimo e máximo. A mediana determina a posição, enquanto a dispersão dos dados é dada pelo desvio interquartílico.

\section{Resultados e Discussão}

Os fatores grupo de solo e data de semeadura não interagiram significativamente quanto ao número de dias com excedente hídrico. No entanto, ambos apresentaram efeito significativo sobre essa variável, em todos os subperíodos analisados e ao longo de todo o ciclo da cultura (Figura 1 e Tabela 3).

Como esperado, as diferentes datas de semeadura, simuladas nos 43 anos de estudo, resultaram em diferentes somas térmicas diárias e, portanto, produziram efeito direto sobre a duração simulada dos subperíodos de desenvolvimento da cultura. Dessa forma, o número de dias com excedente hídrico também variou de acordo com as datas de semeadura (Figura 1), não só pela distribuição diferencial da precipitação, mas, também, pelas diferenças na duração dos subperíodos e do ciclo.

No subperíodo da semeadura à emergência (S-E), o maior número de dias com excedente hídrico ocorreu com a semeadura em 1 de agosto (Figura 1). Segundo Maldaner (2012), a duração desse subperíodo pode estender-se de 11 a 15 dias, de acordo com a menor ou a maior soma térmica diária. Assim, entre as semeaduras precoces, as realizadas de meados de agosto a início de setembro foram as mais adequadas, pois apresentaram menor excesso hídrico, o qual voltou a aumentar na semeadura em meados de setembro. $\mathrm{O}$ excedente hídrico no subperíodo S-E pode reduzir, atrasar e tornar desuniforme a emergência das plântulas e seu crescimento inicial (Yasumoto et al., 2011; Loose, 2013), o que pode ter consequências sobre a produção, uma vez que esta é afetada pela desuniformidade de desenvolvimento e pela redução do estande de plantas (Braz \& Rossetto, 2009). Conforme Yasumoto et al. (2011), fatores determinantes do crescimento e do desenvolvimento do girassol (altura de planta, comprimento e espessura da haste, número de folhas, diâmetro do capítulo, massa seca de raízes e acumulação de nitrogênio) são negativamente afetados quando as plantas ficam sujeitas à saturação do solo por até 4 dias, durante o estabelecimento da cultura, o que resultaria na diminuição do rendimento, da massa de aquênios e do teor de óleo. Silveira et al. (2014) afirmam que ocorrências periódicas de excedente hídrico para o cafeeiro afetam tanto a área foliar quanto o número de folhas.

No subperíodo da emergência ao botão floral visível (E-R1), o número de dias com excesso hídrico foi maior nas duas primeiras datas de semeadura, e o menor valor foi observado para as datas de 16 de novembro a 1 de dezembro (Figura 1). Esse subperíodo abrange todo 

durar de 35 a 60 dias (Maldaner, 2012), dependendo da data de semeadura. Essa variação na duração do
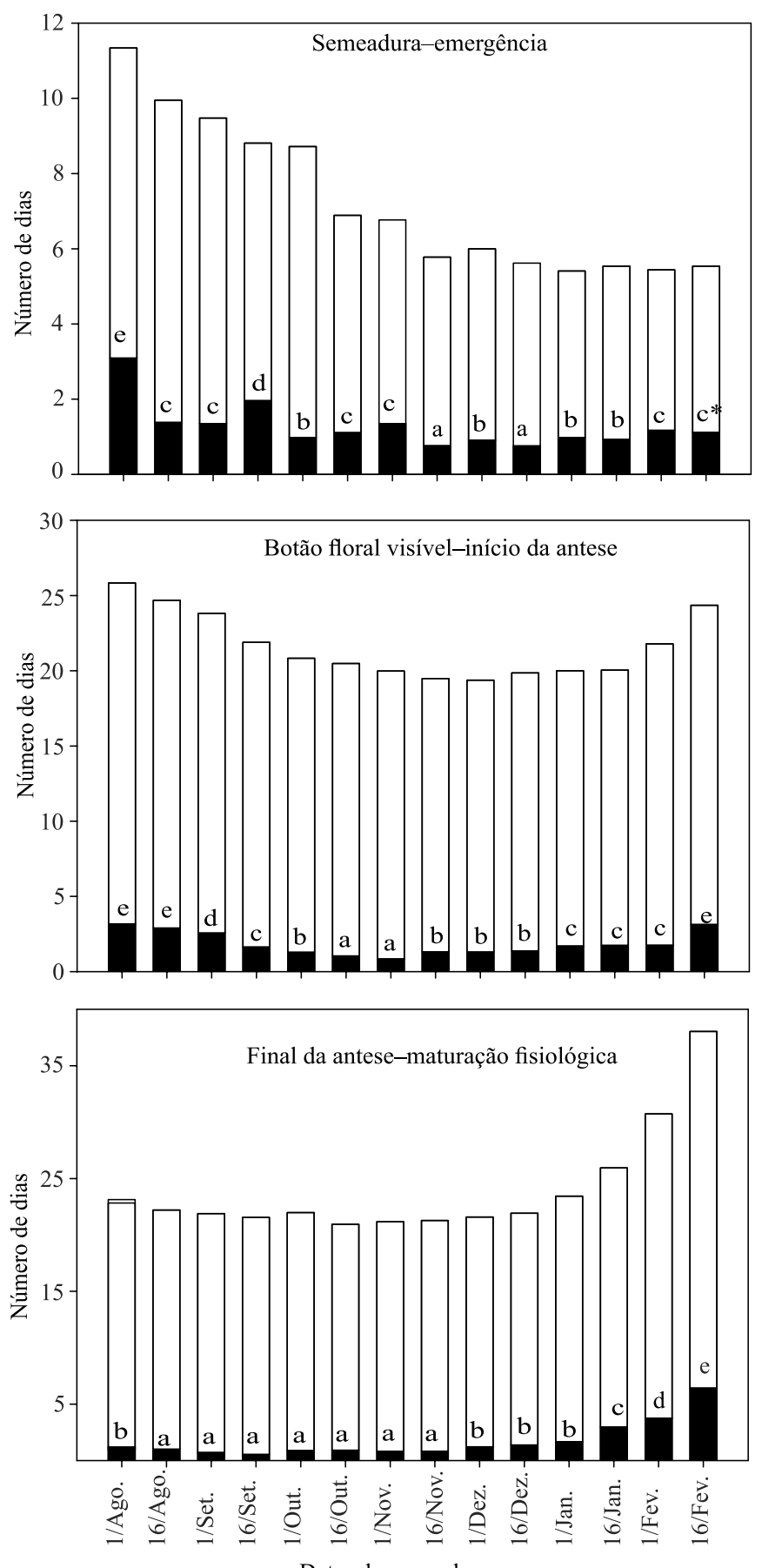

Datas de semeadura o desenvolvimento vegetativo das plantas, que pode

subperíodo E-R14, logicamente, tem efeito direto sobre o número absoluto de dias com excedente hídrico. Nesse subperíodo, a emissão e a expansão das folhas são os
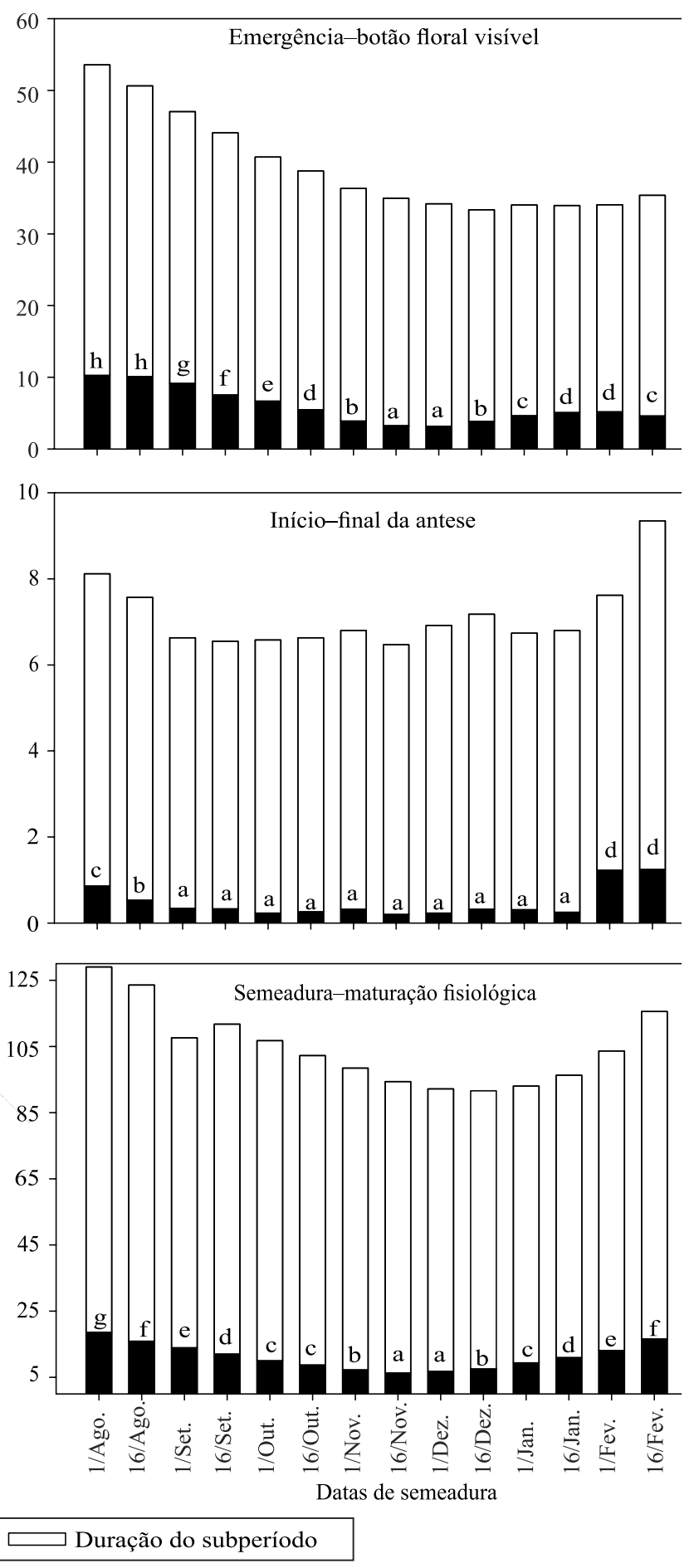

Figura 1. Número médio de dias com excedente hídrico nos subperíodos e no ciclo de desenvolvimento do girassol (Helianthus annuus), de acordo com as 14 datas de semeadura simuladas em cada ano, no período de 1968 a 2011. Médias seguidas de letras iguais não diferem pelo teste de Scott \& Knott, a 5\% de probabilidade. 
principais processos fisiológicos ativos, e o excedente hídrico reduz o potencial de água nas folhas, causando sua murcha, o que afeta diretamente a expansão foliar (Orchard \& Jessop, 1984).

Além do desenvolvimento da parte aérea das plantas, o crescimento do sistema radicular somente ocorre durante o período vegetativo. Loose (2013) observou que plantas de girassol submetidas a excedente hídrico apresentam crescimento superficial de raízes secundárias e adventícias no solo, em detrimento do aprofundamento da raiz principal e do crescimento da parte aérea, o que diminuiria a massa de matéria seca das plantas, principalmente das raízes. Segundo Wample \& Davis (1983), o acúmulo de carboidratos não estruturais nas folhas de girassol sob excedente hídrico é reflexo da redução no transporte, pelo floema, dos fotossintatos que se destinariam às raízes. Assim como o girassol, outras espécies apresentam manifestações fisiológicas ou morfológicas quando submetidas a esse tipo de estresse; algumas são consideradas hipoxi-tolerantes, como a Vitis riparia Michx., que apresenta baixo consumo de ATP nas raízes, o que preveniria o efeito letal do estresse por hipoxia (Mancuso \& Marras, 2006) e seria evidência de um mecanismo de autorregulação que, conforme Irfan et al. (2010), é resultante de variação na expressão genética das plantas.

Após a emissão do botão floral até o início da antese (R1-R5.1), subperíodo que abrange a formação dos órgãos reprodutivos, a maior quantidade de dias com excedente hídrico (Figura 1) foi verificada nas duas primeiras datas de semeadura, em 1 e 16 de agosto, e também na última semeadura, em 16 de fevereiro. Segundo Huynh et al. (2005), as mudanças relacionadas ao estresse ambiental por excesso hídrico, mais facilmente observadas no subperíodo R1-R5.1, ocorrem nas folhas, as quais inicialmente apresentam clorose e necrose, que evoluem até a desfolha total, com cessação do crescimento e morte prematura das plantas. Dat et al. (2004) apontam que o nível de expressão de hormônios de crescimento nas plantas é afetado sob excesso hídrico. Por sua vez, Vartapetian (2006) relata que mudanças morfológicas e fisiológicas, como elongação do caule, desenvolvimento de aerênquima e formação de raízes adventícias, estão possivelmente associadas ao aumento na produção de etileno, à semelhança do que ocorre na queda das folhas pelo efeito da concentração desse hormônio (Gil et al., 2009).

Os diferentes tipos de solos avaliados produziram efeito significativo sobre o número médio de dias com excedente hídrico nos subperíodos de desenvolvimento e do ciclo da cultura (Tabela 3). O grupo de solos Savence (Argisolo em São Pedro; Chernossolo em Venda Grande; e Latossolo em Cerrito) esteve relacionado à maior duração no subperíodo R6-R9 e no ciclo completo. As características físicas do solo podem modular as respostas das plantas ao excedente hídrico (Grassini et al., 2007). Dessa forma, solos argilosos e deficientes em drenagem deixariam as plantas mais expostas a esse tipo de estresse, por ficarem por mais tempo sob condições de saturação; já solos estruturados e bem drenados permitem a difusão do oxigênio para camadas mais profundas (Young \& Crawford, 2004).

Os grupos de solos Oagabri (Argissolo em Oásis; e Planossolo em São Gabriel) e Alcampi (Argissolo em Alto das Canas; e Luvissolo em Cambaí) apresentaram a menor quantidade de dias com excedente hídrico, para todos os subperíodos avaliados e, consequentemente, para todo o ciclo de desenvolvimento da cultura (Tabela 3 ). Tanto a CAD de cada grupo de solo, quanto a precipitação efetiva em cada local, são determinantes na diferenciação entre os grupos de solos. Porém, é importante destacar que os

Tabela 3. Número médio de dias com excedente hídrico, nos subperíodos de desenvolvimento da cultura do girassol (Helianthus annuus), obtido por análise numérica, para os diferentes grupos de solos, em cada ano do período de 1968 a $2011^{(1)}$

\begin{tabular}{|c|c|c|c|c|c|c|}
\hline \multirow[t]{2}{*}{ Grupo de solo ${ }^{(2)}$} & \multicolumn{6}{|c|}{ Subperíodo de desenvolvimento ${ }^{(3)}$} \\
\hline & S-E & E-R1 & R1-R5.1 & R5.1-R6 & R6-R9 & S-R9 \\
\hline Oagabri & $1,02 \mathrm{a}$ & $5,39 \mathrm{a}$ & $1,43 a$ & $0,32 \mathrm{a}$ & $1,26 \mathrm{a}$ & $9,44 a$ \\
\hline Alcampi & $1,29 b$ & $5,60 \mathrm{a}$ & $1,48 \mathrm{a}$ & $0,32 \mathrm{a}$ & $1,26 \mathrm{a}$ & $9,92 \mathrm{a}$ \\
\hline Chaci & $1,34 b$ & $6,07 \mathrm{~b}$ & $1,74 \mathrm{~b}$ & $0,43 \mathrm{a}$ & $1,72 b$ & $11,31 b$ \\
\hline Savence & $1,45 b$ & $6,35 b$ & $2,24 \mathrm{c}$ & $0,63 b$ & $2,28 \mathrm{c}$ & $12,93 \mathrm{c}$ \\
\hline Santamaria & $1,28 b$ & $6,08 \mathrm{~b}$ & $2,09 \mathrm{c}$ & $0,62 b$ & $2,00 \mathrm{~b}$ & $12,05 b$ \\
\hline Vacacaí & $1,27 \mathrm{~b}$ & $5,99 \mathrm{~b}$ & $2,01 \mathrm{c}$ & $0,53 b$ & $1,87 \mathrm{~b}$ & $11,69 \mathrm{~b}$ \\
\hline
\end{tabular}

${ }^{(1)}$ Médias seguidas de letras iguais, nas colunas, não diferem pelo teste de Scott \& Knott, a 5\% de probabilidade. (2)Oagabri, Oásis e São Gabriel; Alcampi, Alto das Canas e Cambaí; Chaci, Charrua, Ciríaco, Guassupi e Júlio de Castilhos; Savence, São Pedro, Venda Grande e Cerrito; Santamaria, Santa Maria; Vacacaí, Vacacaí. ${ }^{(3)}$ S-E, semeadura-emergência; E-R1, emergência-botão floral visível; R1-R5.1, botão floral visível-início da antese; R5.1-R6, início da antese-final da antese; R6-R9, final da antese-maturação fisiológica; e S-R9, ciclo de desenvolvimento inteiro. 
solos avaliados estavam sob uma mesma área de estudos, abangida pela Estação Climatológica Principal de Santa Maria, tendo-se considerado, para simulação, a mesma condição de precipitação pluvial.
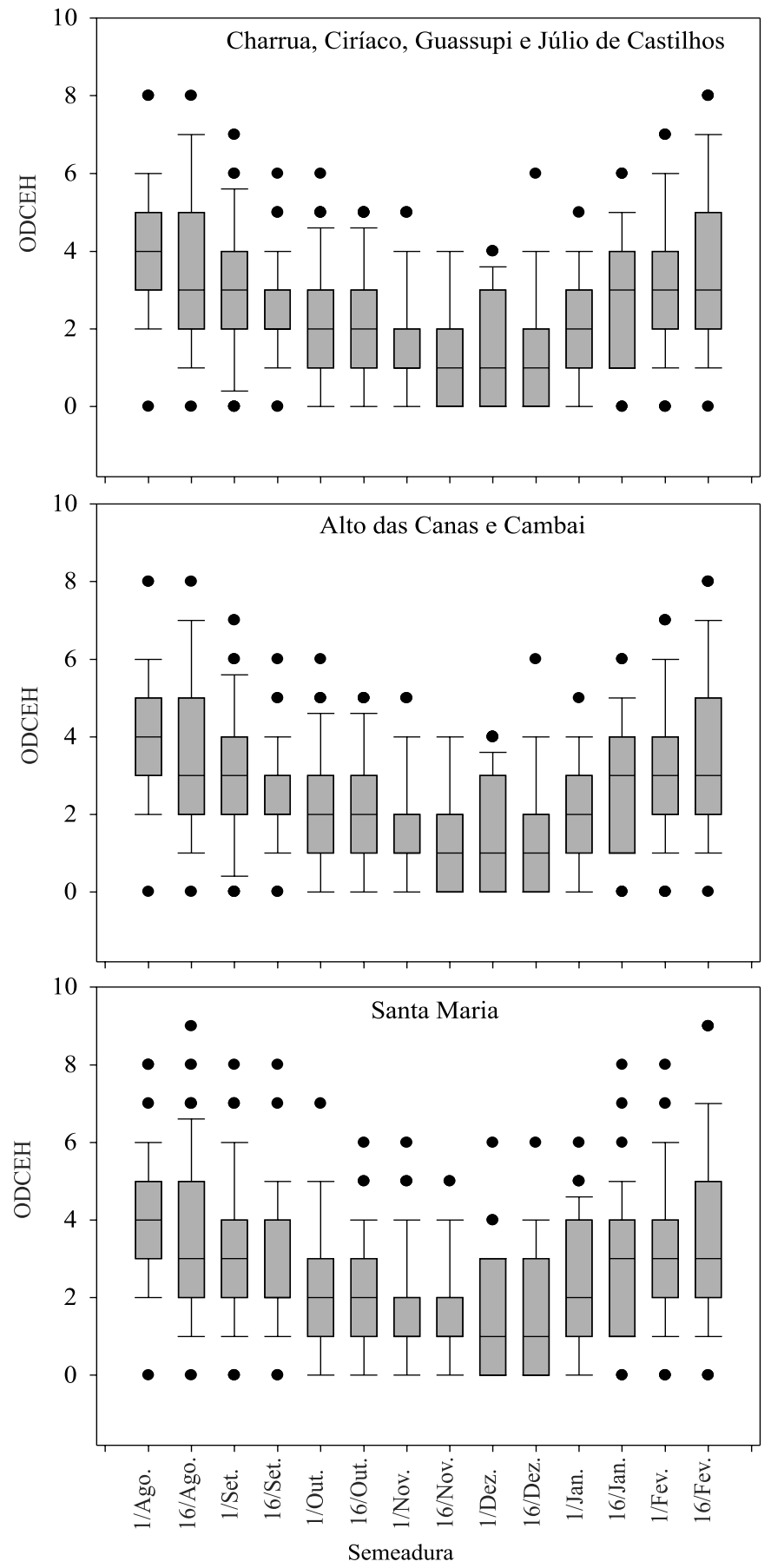

Observou-se grande variabilidade na ocorrência de 2 ou 4 dias consecutivos com excedente hídrico (ODCEH), de acordo com as diferentes datas de semeaduras (Figuras 2 e 3). No geral, as três primeiras datas de semeadura,
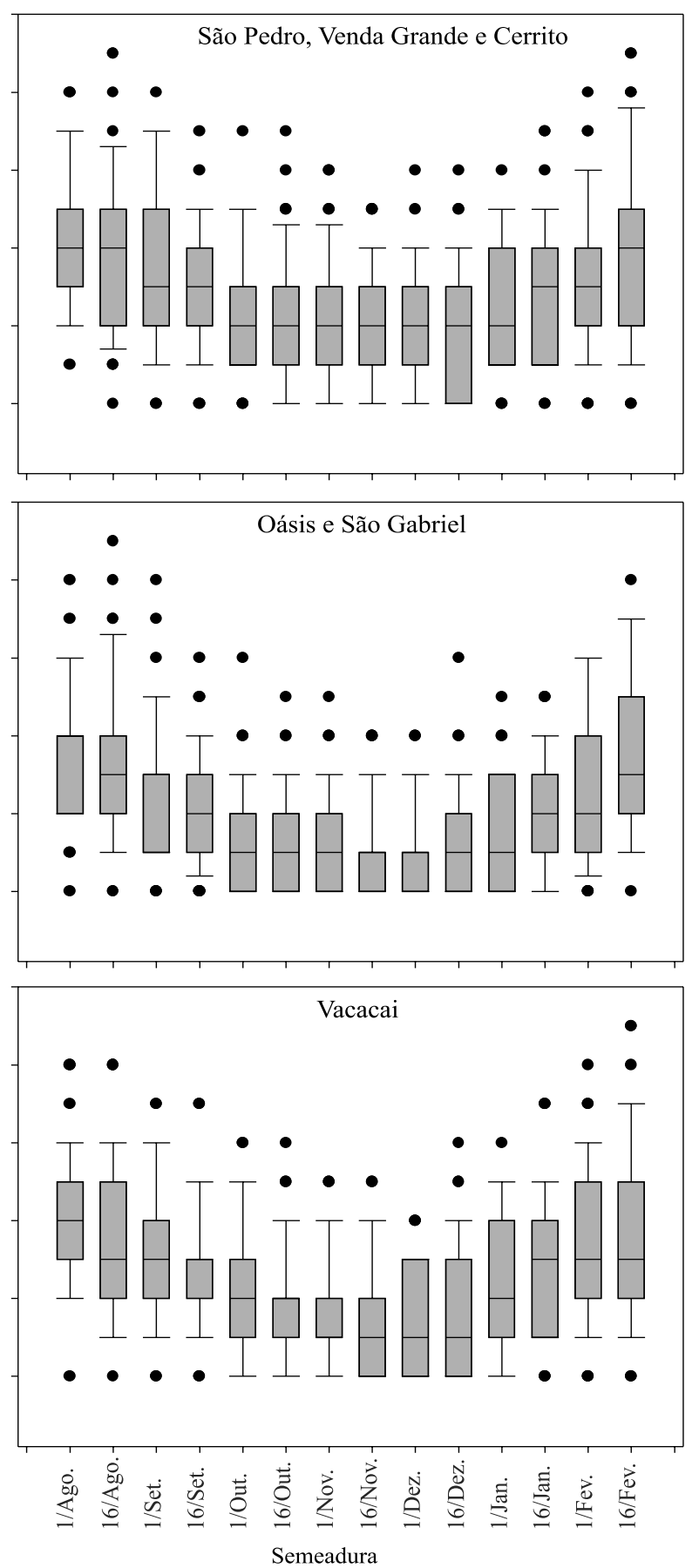

Figura 2. Ocorrências iguais ou superiores a 2 dias consecutivos com excedente hídrico (ODCEH) ao longo do ciclo de desenvolvimento do girassol (Helianthus annuus), de acordo com seis grupos de solos e 14 datas de semeadura simuladas de 1968 a 2011. Os pontos preenchidos representam os valores discrepantes máximos ou mínimos, que ocorreram nas simulações avaliadas. 

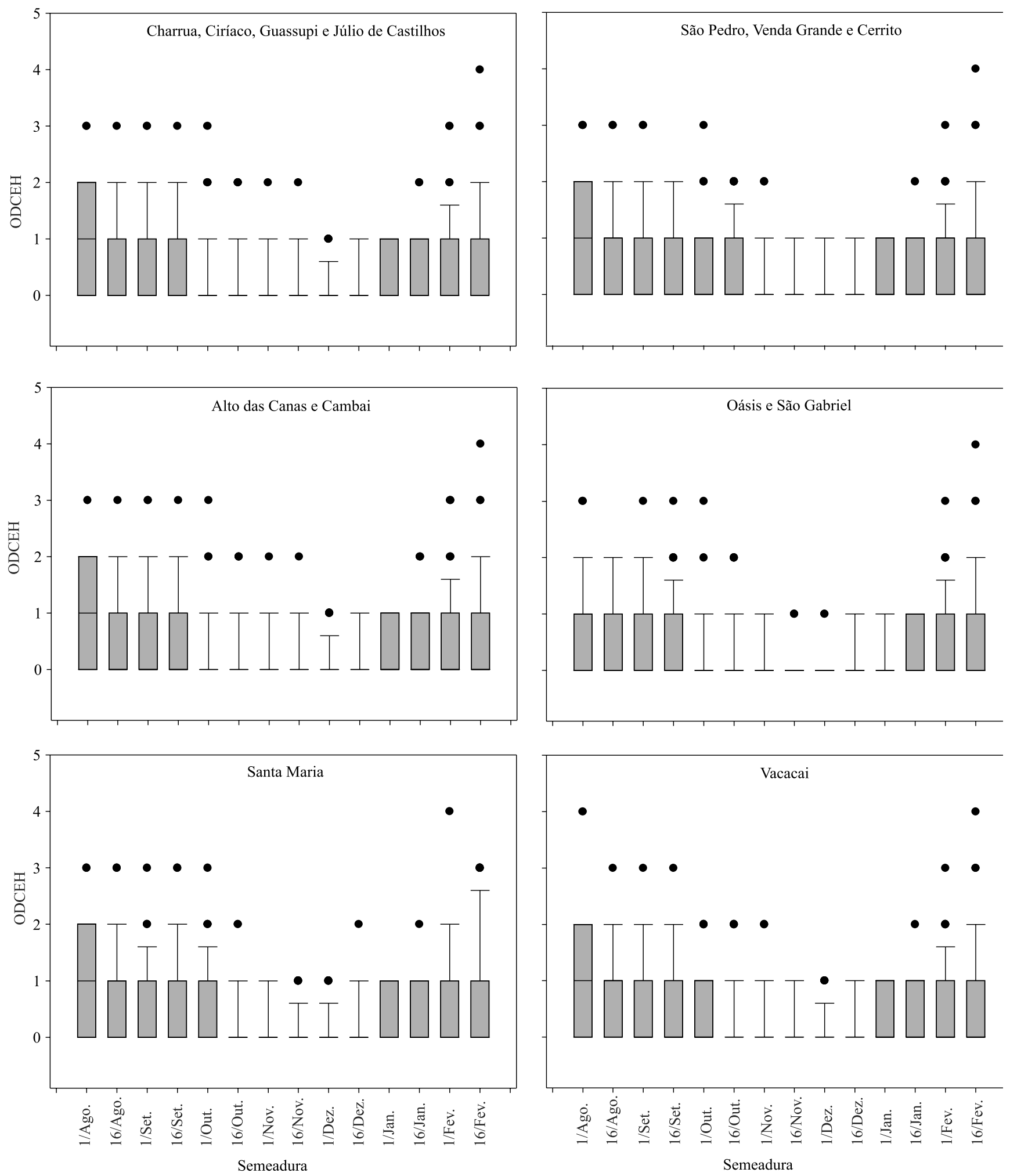

Figura 3. Ocorrências iguais ou superiores a 4 dias consecutivos com excedente hídrico (ODCEH) ao longo do ciclo de desenvolvimento do girassol (Helianthus annuus), de acordo com seis grupos de solos e 14 datas de semeadura simuladas de 1968 a 2011. Os pontos preenchidos representam os valores discrepantes máximos ou mínimos, que ocorreram nas simulações avaliadas. 
juntamente com as duas últimas, apresentaram os maiores valores de OCDEH iguais ou superiores a 2 dias (Figura 2). Esta variável está corrrelacionada com a duração do ciclo da cultura, pois quanto maior for este, maior será o tempo em que as plantas estarão sujeitas à ocorrência do excesso hídrico no solo. A predominância de excedente hídrico nas datas de semeadura relatadas decorre da baixa demanda evapotranspirativa da atmosfera nesses períodos (Heldwein et al., 2009).

Para o grupo de solos nas unidades de mapeamento Charrua, Ciríaco, Guassupi e Júlio de Castilhos, a semeadura em 16 de setembro resultou nos menores valores de OCDEH superiores a 2 dias (Figura 2), bem como em menor dispersão, em comparação às semeaduras realizadas mais cedo. Já para os valores de OCDEH iguais ou superiores a 4 dias, a semeadura de 1 de agosto apresentou a maior dispersão nos valores (Figura 3), com exceção dos solos em Oásis e São Gabriel. De acordo com os dados, para esta data de semeadura, em $50 \%$ dos casos são esperadas até duas ocorrências de 4 ou mais dias consecutivos com excesso hídrico ao longo do ciclo.

Apesar de raros, houve registros de até nove ODCEH iguais ou superiores a 2 dias (pontos preenchidos na Figura 2), para algumas datas de semeadura nos diferentes grupos de solos, e de até quatro ODCEH iguais ou superiores a 4 dias (pontos preenchidos na Figura 3 ).

\section{Conclusões}

1. A limitação ao cultivo de girassol (Helianthus annuus) pela ocorrência de excedentes hídricos varia de acordo com a data de semeadura e com o tipo de solo avaliado.

2. A persistência de dias consecutivos com excedente hídrico e a duração do ciclo de desenvolvimento da cultura são influenciados pela data de semeadura.

\section{Agradecimentos}

Ao Conselho Nacional de Desenvolvimento Científico e Tecnológico (CNPq, processo 140899/2011), pelo apoio financeiro.

\section{Referências}

BRAZ, M.R.S.; ROSSETTO, C.A.V. Estabelecimento de plântulas e desempenho de plantas em resposta ao vigor dos aquênios de girassol. Ciência Rural, v.39, p.1997-2003, 2009. DOI: 10.1590/ S0103-84782009000700007.
BURIOL, G.A.; ESTEFANEL, V.; SWAROWSKY, A.; D'AVILA, R.F. Homogeneidade e estatísticas descritivas dos totais mensais e anuais de chuva de Santa Maria, Estado do Rio Grande do Sul. Revista Brasileira de Recursos Hídricos, v.11, p.89-97, 2006.

CARDOSO, C.D.V. Probabilidade de ocorrência de deficiência hídrica nos solos da região Central do Estado do Rio Grande do Sul. 2005. 162p. Tese (Doutorado) - Universidade Federal de Santa Maria, Santa Maria.

DAT, J.F.; CAPELLI, N.; FOLZER, H.; BOURGEADE, P.; BADOT, P.-M. Sensing and signaling during plant flooding. Plant Physiology and Biochemistry, v.42, p.273-282, 2004. DOI: 10.1016/j.plaphy.2004.02.003.

FAGUNDES, J.D.; SANTIAGO, G.; MELlO, A.M. de; BELLÉ, R.A.; STRECK, N.A. Crescimento, desenvolvimento e retardamento da senescência foliar em girassol de vaso (Helianthus annuus L.): fontes e doses de nitrogênio. Ciência Rural, v.37, p.987-993, 2007. DOI: 10.1590/S0103-84782007000400011.

FRIZZONE, J.A.; ANDRADE JÚNIOR, A.S. de. (Ed.). Planejamento de irrigação: análise de decisão de investimento. Brasília: Embrapa Informação Tecnológica, 2005. 626p.

GIL, P.M.; GUROVICH, L.; SCHAFFER, B.; GARCÍA, N.; ITURRIAGA, R. Electrical signaling, stomatal conductance, ABA and ethylene content in avocado trees in response to root hypoxia. Plant Signaling and Behavior, v.4, p.100-108, 2009. DOI: 10.4161/psb.4.2.7872.

GILMORE, E.C.; ROGERS, J.S. Heat units as a method of measuring maturity in corn. Agronomy Journal, v.50, p.611-615, 1958. DOI: 10.2134/agronj1958.00021962005000100014x.

GRASSINI, P.; INDACO, G.V.; PEREIRA, M.L.; HALL, A.J.; TRÁPANI, N. Responses to short-term waterlogging during grain filling in sunflower. Field Crops Research, v.101, p.352-363, 2007. DOI: 10.1016/j.fcr.2006.12.009.

HELDWEIN, A.B.; BURIOL, G.A.; STRECK, N.A. O clima de Santa Maria. Ciência \& Ambiente, v.38, p.43-58, 2009.

HUYNH, L.N.; VANTOAI, T.; STREETER, J.; BANOWETZ, G. Regulation of flooding tolerance of SAG12:ipt Arabidopsis plant by cytokinin. Journal of Experimental Botany, v.56, p.1397-1407, 2005. DOI: $10.1093 / \mathrm{jxb} /$ eri141.

IRFAN, M.; HAYAT, S.; HAYAT, Q.; AFROZ, S.; AHMAD, A. Physiological and biochemical changes in plants under waterlogging. Protoplasma, v.241, p.3-17, 2010. DOI: $10.1007 /$ s00709-009-0098-8.

JACKSON, M.B.; COLMER, T.D. Response and adaptation by plants to flooding stress. Annals of Botany, v.96, p.501-505, 2005. DOI: $10.1093 / \mathrm{aob} / \mathrm{mci} 205$.

LOOSE, L.H.; LONG, M.E.F.; CARNELOS, D.; MURPHY, G.M. Variabilidade dos rendimentos de girassol na Argentina em função da variabilidade climática interanual. Revista de la Facultad de Agronomía UBA, v.30, p.169-178, 2010.

LOOSE, L.H. Emergência e crescimento inicial de plantas de girassol sob excesso hídrico. 2013. 99p. Dissertação (Mestrado) Universidade Federal de Santa Maria, Santa Maria.

MALDANER, I.C. Probabilidade de ocorrência de deficiência hídrica na cultura do girassol na região central do Rio Grande 
do Sul. 2012. 141p. Tese (Doutorado) - Universidade Federal de Santa Maria, Santa Maria.

MANCUSO, S.; MARRAS, A.M. Adaptative response of Vitis root to anoxia. Plant and Cell Physiology, v.47, p.401-409, 2006. DOI: 10.1093/pcp/pcj007.

ORCHARD, P.W.; JESSOP, R.S. The response of sorghum and sunflower to short-term waterlogging. I. Effects of stage of development and duration of waterlogging on growth and yield. Plant and Soil, v.81, p.119-132, 1984. DOI: 10.1007/ BF02206901.

SAS INSTITUTE. SAS/STAT user's guide. Version 8.2. Cary: SAS Institute, 2001.

SAUE, T.; KADAJA, J. Modeling crop yield response to precipitation redistribution on slopes. Biologia, v.64, p.502-506, 2009. DOI: $10.2478 / \mathrm{s} 11756-009-0103-x$.

SILVA, J.C. da; HELDWEIN, A.B.; TRENTIN, G.; STRECK, N.A.; MARTINS, F.B. Funções de distribuição de probabilidade decendial e mensal para a deficiência hídrica no solo. Ciência Rural, v.38, p.1893-1899, 2008. DOI: 10.1590/S010384782008000700014.

SILVEIRA, H.R. de O.; SANTOS, M. de O.; ALVES, J.D.; SOUZA, K.R.D. de; ANDRADE, C.A.; ALVES, R.G.M. Growth effects of water excess on coffee seedlings (Coffea arabica L.). Acta Scientiarum. Agronomy, v.36, p.211-218, 2014. DOI: 10.4025/actasciagron.v36i2.17557.

THORNTHWAITE, C.W.; MATHER, J.R. The water balance. Centerton: Drexel Institute of Technology, 1955. 104p. (Publications in climatology, v.8, n.1).

VARTAPETIAN, B.B. Plant anaerobic stress as a novel trend in ecological physiology, biochemistry, and molecular biology: 2. Further development of the problem. Russian Journal of Plant Physiology, v.53, p.711-738, 2006. DOI: 10.1134/ S102144370606001X.

YASUMOTO, S.; TERAKADO, Y.; MATSUZAKI, M.; OKADA, $K$. Effects of high water table and short-term flooding on growth, yield, and seed quality of sunflower. Plant Production Science, v.14, p.233-248, 2011. DOI: 10.1626/pps.14.233.

YOUNG, I.M.; CRAWFORD, J.W. Interactions and self-organization in the soil-microbe complex. Science, v.304, p.1634-1637, 2004. DOI: 10.1126/science.1097394.

WAMPLE, R.L.; DAVIS, R.W. Effect of flooding on starch accumulation in chloroplasts of sunflower (Helianthus annuus L.).

Plant Physiology, v.73, p.195-198, 1983. DOI: 10.1104/ pp.73.1.195.

Recebido em 11 de julho de 2014 e aprovado em 18 de maio de 2015 